\title{
Se-Won Lim and Standardized Suicide Prevention Program for Gatekeeper Intervention in Korea (Bogo Deudgo Malhagi, Suicide CARE)
}

\author{
Hwa-Young Lee ${ }^{\bowtie}$ \\ Department of Psychiatry, College of Medicine, Soonchunhyang University, Cheonan Hospital, Cheonan, Republic of Korea
}

Prof. Se-Won Lim (Figure 1) played a pivotal role in creating the Standardized Suicide Prevention Program for Gatekeeper Intervention in Korea. Korean people call this program Bogo Deudgo Malhagi. 'Bogo' means 'looking' (Careful observation). 'Deudgo' means 'listening' (Active listening). 'Malhagi' means 'talking' (Risk evaluation \& Expert referral). Its acronym in Korean is BODEUDMAL. This acronym in English is Suicide CARE (Careful observation, Active listening, Risk evaluation \& Expert referral). Previously, some researchers translated 'Bogo Deudgo Malhagi' into 'Watch, Listen and Talk.' In the 'Mental Health ATLAS 2017' published by the World Health Organization, it was translated into 'Seeing, Listening, and Speaking.' From now on, the Bogo Deudgo Malhagi development team decided to call the English name of the Bogo Deudgo Malhagi program 'Suicide CARE.'

Prof. Se-Won Lim was born in Daejeon city, South Korea. He graduated from Chungnam High School and Korea University School of Medicine. He wanted to become a thoracic surgeon. However, after he recognized that his hand skill was poor, he decided to become a psychiatrist. He completed his residency at the Department of Psychiatry, Korea University Guro Hospital. While working as a clinical instructor at Korea University Anam Hospital, his subspecialty was depression highly related to suicide care. After that, he became a full-time professor at Sungkyunkwan University Kangbuk Samsung Hospital.

There was an anecdote in which he became interested in

Received: October 12, 2020 Accepted: October 23, 2020

$\square$ Correspondence: Hwa-Young Lee, MD, PhD

Department of Psychiatry, College of Medicine, Soonchunhyang University, Cheonan Hospital, 31 Suncheonhyang 6-gil, Dongnam-gu, Cheonan 31151, Republic of Korea

Tel: +82-41-570-2280, E-mail: leehway@gmail.com

(a) This is an Open Access article distributed under the terms of the Creative Commons Attribution Non-Commercial License (https://creativecommons.org/licenses/bync/4.0) which permits unrestricted non-commercial use, distribution, and reproduction in any medium, provided the original work is properly cited. depression and suicide. In his second year of residency, an elderly woman who had been hospitalized for depression with suicidal thoughts visited his outpatient clinic for the first time after discharge. The elderly woman showed a different behavior than usual when she went out of the office, saying she wanted to say to him "Thank you very much so far." He felt something strange. Her face did not look depressed. At that time, he was too busy to hear her anymore and she left. A few days later, the elderly woman's son came and said she committed suicide and said he needed his mother's medical record of depression for legal process. Professor Lim reproached himself and felt despaired again. He accused himself of having poor hands and poor judgment. Thus, he became interested in depression and suicide prevention. After about ten years, he developed a suicide prevention program (Bogo Deudgo Malhagi).

Year 2011, Starting point.

In 2011, Bogo Deudgo Malhagi, the Standardized Suicide Prevention Program for Gatekeeper Intervention in Korea was developed by the Education Committee of Korea Suicide Prevention Association led by Professor Se-Won Lim with support of Korean Life Insurance Philanthropy Foundation. ${ }^{3}$ The Ministry of Health and Welfare and the Central Suicide Prevention Center were in charge of disseminating the program.

The development of this program began when Professors Se-Won Lim, Jong-Woo Baek, and Jae-Won Kim gathered at Haklim Cafe in Daehak-Ro, Seoul, South Korea and draw a symbolic design with eyes, ears, and mouth (Figure 2A). That eye, ear, and mouth design is still used as a symbol of Suicide CARE (Bogo Deudgo Malhagi) (Figure 2B-D). In research conducted in the year following development, a statistically significant result was obtained in a study to evaluate the effectiveness of Suicide CARE. ${ }^{4}$

During the development of the program, Professor Se-Won Lim suffered sudden back pain. As the pain intensified, he ex- 
perienced depression. He experienced severe depression and suicidal thoughts. After overcoming his symptoms, he wrote a book, "Nobody wants to die." In the meantime, professor Lim has wondered what true hope is. Despite severe pain, he worked with enthusiasm so that his insight into depression and deep insight into true hope could be reflected in the program. He took the lead in encouraging more people to protect each other from suicide through "Suicide CARE" program.

In 2015, with the support of the Ministry of Health and Welfare, a 1.6W version was developed for Korean workers. By analyzing characteristics related to suicide of office workers, a tailored education program for office workers consisting of cases of women in their 20 s and men in their 40 s was completed. This promoted suicide prevention education for each company and community, leading "Suicide CARE" program to become a program at national level.

In 2016, Prof. Se-Won Lim developed the first Suicide Prevention Program for Gatekeeper Intervention for the Korean Air Force. This program was subsequently adopted as the official program by the Ministry of National Defense. This gave all soldiers a chance to receive a suicide prevention program for gatekeeper intervention. Afterwards, Army and Navy versions were completed in 2018 at the request of the Ministry of

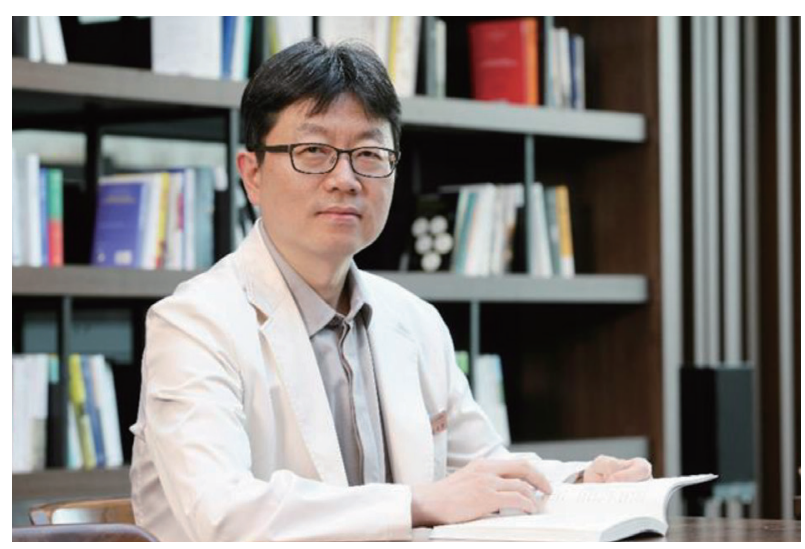

Figure 1. Photograph of prof. Se-Won Lim.
National Defense. In recognition of his achievements in developing the suicide prevention education program, he received a plaque of appreciation from the army and a Life Love Grand Prize from the Korean Suicide Prevention Association.

Unfortunately, on December 31, 2018, Prof. Se-Won Lim passed away in an accident. It was a surprise to everyone in the country, especially patients who received his care. They expressed their condolences. Since his death, several plaques and awards have been awarded for his remarkable achievements, including Blue Stripes Order of Service Merit.

In 2019, Korean NeuroPsychiatric Association (KNPA) ask a singer Chang-gi Kim who is a psychiatrist to write and compose a memorial song 'A Story to Tell on the Day We Meet Again' for the late Professor Se-won Lim, ${ }^{6}$ and YTN Broadcast held the 2019 Lim Se-won memorial concert, 'Nobody Wants to Die."

In 2019, following the will of Professor Se-Won Lim, program members of the Korea Suicide Prevention Association completed the Marine Corps version of the program through voluntary participation. As a result, all four military versions of customized suicide prevention training programs reflecting characteristics of each army have been developed. Now, suicide prevention program for gatekeeper intervention is provided to all soldiers. In addition, a suicide prevention program for gatekeeper intervention was developed for firefighters in 2019. Customized education programs are being developed for each job.

With the support of the Ministry of Health and Welfare, the Central Suicide Prevention Center and Soonchunhyang University revised version 2.0 of "Suicide CARE" program. Evidence-based Standardized Suicide Prevention Program for Gatekeeper Intervention in Korea was revised based on feedback from instructors, latest domestic and foreign research results, and psychological autopsy results from Korea Psychological Autopsy Center. In the revised program, compositions of the program 1.0 to 1.6 were maintained, with various details for gate-keepers to actively participate in the program. Efforts


Figure 2. Change of characterized images for Standardized Suicide Prevention Program for Gatekeeper Intervention in Korea (BODEUDMAL, Suicide CARE). A: Draft design. B: Version 1.0 to 1.6. C: Version of Air Force. D: Version 2.0. 
have been made to further maximize the effectiveness of video education in Suicide CARE 2.0 revision process.

Since the development of the Suicide CARE, about 1.3 million people have received the Suicide CARE program in Korea. It was the amazing dedication and passion of the development committee that made it possible. Particularly, I would like to express my sincere respect and gratitude to Professor SeWon Lim who has shown a stronger passion than anyone else.

He was sacrificed while trying to save another person even to the last dangerous moment. In recognition of this, the Korean government designated him as a righteous dead person in $2020 .^{8}$

We sincerely hope that Professor Se-Won Lim's hopeful message from his book 'Nobody wants to die' will be delivered to the world through the 'Suicide CARE' program.

\section{Acknowledgments}

I would like to express our sincere gratitude to Prof. Se-Won Lim for his dedication to the development of "Suicide CARE" versions 1.0 and 1.6.

\section{Conflicts of Interest}

The author has no potential conflicts of interest to disclose.

\section{ORCID iD}

Hwa-Young Lee

https://orcid.org/0000-0002-2749-6232

\section{REFERENCES}

1. Lee SU, Park JI, Lee S, Oh IH, Choi JM, Oh CM. Changing trends in suicide rates in South Korea from 1993 to 2016: a descriptive study. BMJ Open 2018;8:e23144.

2. World Health Organization. Mental Health Atlas 2017 Member State Profile: Republic of Korea. Geneva: World Health Organization; 2018, p.358-363.

3. Korean Association of Suicide Prevention. Suicide CARE (Standardized Suicide Prevention Program for Gatekeeper Intervention in Korea) version 1.0. Seoul, Korea: Korea Association for Suicide Prevention; 2011.

4. Paik JW, Jo SJ, Lee S, Ong JY, Park JI. The effect of Korean standardized suicide prevention program on intervention by gatekeepers. J Korean Neuropsychiatr Assoc 2014;53:358-363.

5. Lim SW. Nobody Wants to Die. Seoul, Korea: Alkeybook; 2016.

6. Korean NeuroPsychiatric Association. A memorial song 'A Story to Tell on the Day We Meet Again' for the late Professor Se-won Lim. 2019. Available at: https://youtu.be/j5spMWN6Mlo.

7. YTN. 2019 Se-won Lim memorial concert, 'Nobody Wants to Die. Available at: https://youtu.be/G7fjD69gQa0.

8. At the end of two years ago, the late Professor Se-won Lim, who was attacked and killed by a patient at Gangbuk Samsung Hospital, was recognized as a rightous dead person. Seoul: Ministry of Health and Welfare; Sep 24, 2020. 